\title{
LA SOCIEDAD WAYUU: MODO DE VIDA Y PRINCIPIOS CONSUETUDINARIOS EN EL CONTEXTO REPUBLICANO
}

\author{
Carmen Laura Paz Reverol
}

Universidad del Zulia, Maracaibo

\section{Resumen:}

Para la sociedad Wayuu, las leyes y costumbres han sido, en su proceso histórico, factores claves de cohesión social y definición de su especificidad cultural. Después del arribo de los europeos, aquella sociedad incorporó a su modo de vida nuevas tecnologías y prácticas económicas, sin perder sus principales rasgos "identitarios" y autonómicos. De ahí que sus relaciones con los poderes español y republicano debieron ser reguladas por éstos, a objeto de resolver las fricciones entre las "parcialidades indígenas" y las autoridades de la Provincia de Maracaibo. Estas medidas, orientadas a la "reducción, pacificación y civilización" de la sociedad Wayuu, ocasionaron acciones violentas; los indígenas, mediante "incursiones" y "tropelías" defendieron su territorio y recursos naturales. Esta actitud beligerante y consecuente con su organización social y leyes consuetudinarias, ha dado permanencia en el tiempo a un modo de vida sustentado en una particular cosmovisión.

Palabras Clave: Wayuu, modo de vida, resistencia, Guajira, Maracaibo, Venezuela.

\begin{abstract}
For the Wayuu society the laws and customs have been in their historical process key factors of social cohesión and definition of their cultural specificity. After the arrival of the European, that society incorporated to its way of life new technologies and
\end{abstract}




\section{EL TALLER DE LA HISTORIA 2}

economic practices, without losing its main "identitarios" and autonomic characteristics. For that reason their relations with the powers Spanish and republican had to be regulated by these to solve the frictions between the "indigenous parcialidades" and the authorities of the Province of Maracaibo. These measures oriented to the "reduction, pacification and civilization" ofthe Wayuu society caused violent actions; the natives by means of incursions" and "outrages" defended their territory and natural resources. This belligerent and consequet attitude with its social organization and "consuetudinarias" laws has given permanence in the time to way of life sustained in a particular cosmovisión.

Key Words: Wayuu, identity, resistence, Guajira, Maracaibo, Venezuela.

\section{INTRODUCCIÓN}

La especificidad de las entidades históricas que se conformaron, y en algunos casos se consolidaron, antes de emerger Venezuela como Estado, fue un factor que incidió en la poca legitimación de la nueva propuesta republicana, ante las marcadas diferencias de las regiones históricas "con especificidad y ritmos históricos propios". Se agregaba la particularidad de las sociedades indígenas y comunidades negras, específicamente los habitantes de la Península de la Guajira. La Provincia de Maracaibo debió encargarse de concretar las medidas del Estado venezolano hacia esas colectividades (Cardozo, 1991:11). El análisis de esta temática, se realizó mediante el registro y análisis de fuentes documentales localizadas en el Archivo Histórico del Estado Zulia (Maracaibo), Archivo General de la Nación (Caracas, Venezuela), Archivo Central de la Cancillería, Ministerio de Relaciones Exteriores, (siglo XIX). Igualmente, fuentes hemerográficas Biblioteca Tulio Febres Cordero, Hemeroteca Nacional y Academia Nacional de la Historia.

El período de relativa paz permitió, a partir de 1840, aprobar medidas para incorporar a los indígenas al nuevo Estado. En este marco, requirió leyes especiales para los habitantes de la Guajira 
por su singularidad cultural. Una de las preocupaciones principales fue lograr el control del estratégico territorio de la Guajira y minimizar la reacción de los Wayuu ante los métodos utilizados para su "reducción y civilización"; estos intentos no fueron fáciles, estaban enmarcados en un complejo proceso de edificación del Estado republicano y había que atender las contradicciones sociales legadas por el Estado monárquico español y colombiano. Los dirigentes políticos enfrentaron el desafío de consolidar el nuevo sistema republicano en una sociedad multicultural, pluriétnica y descentralizada.

A inicios de la República, el indígena, como sujeto social activo, generó procesos de interacción cultural e identidad que los hacía pertenecer a "sistemas multiétnicos" reconocidos parcialmente por el Estado Venezolano (Amodio, 1993:1). El proceso histórico demuestra que los grupos sociales mantuvieron una sostenida lucha por mantener su cultura y sobrevivir. Se considera en este contexto la intensificación de los procesos de homogeneización que produjeron asimilaciones y resistencias socioculturales. La identidad étnica Wayuu resultante se explica en función de un campo complejo donde interactúan "diversos procesos de conformación del sentido de la vida, representaciones sociales heterogéneas" (Valenzuela Arce, 1996:215).

\section{CLANES O PARCIALIDADES DE LA SOCIEDAD WAYUU EN EL SIGLO XIX}

Según las fuentes de la época, los Wayuu se organizaban socialmente en "parcialidades" o clanes de descendencia matrilineal. Esta forma de organización social no es otra cosa que "reuniones de familia unidas por el parentesco de enlaces inmediatos, para la común seguridad y defensa, ${ }^{1}$ esta estructura permitía mantener cierta

1. "Reseña sobre los usos y costumbres de los indígenas goajiros e indicaciones para su reducción y civilización”. En: El Zulia Ilustrado, Maracaibo, 30 de noviembre de 1890:193, $\mathrm{N}^{\mathrm{O}} 24$. 
cohesión social "como una especie de fuerza que mantiene unidos a los grupos. Se basa particularmente en las reglas que ordenan la vida social y la necesidad del hombre de estar en comunidad" (Amodio, 1988:58). La identidad ancestral de la sociedad Wayuu constituye un elemento importante para la comprensión de su proceso histórico, esta sociedad generó un profundo sentimiento de pertenencia a su respectiva parcialidad, espacio territorial y costumbres tradicionales.

Son muy variadas las estimaciones de la población indígena Wayuu que practicaba sus modos de vida tradicionales. Las parcialidades que se conocían para la época eran la Hipoana (Iipuana), Huriana (Uliana), Hurariyú (Uraliyuu), Jusayú (Juusayuu), Jarariyú (Ja'yaliyuu), Epiayú (Epiayuu), Pusaina (Pushaina), Arpusiana (Aapüshana), Epinayú (Epinayuu), Zapoana (Sapuwana), y Arpureche $^{2}$. Cada una de ellas estaban asentadas en diferentes áreas de la península de la Guajira, territorio considerado sagrado; la cultura oral justificaba su ubicación en función de su origen mítico y cosmogónico ${ }^{3}$.

Rafael E. Benítez que recorre en varios viajes el territorio de la Guajira ha dejado un sugestivo testimonio documental acerca

2. Comunicado titulado GOAJIRA. En: Diario de Avisos y Semanario de las Provincias, Caracas 27 de febrero de $1858, \mathrm{~N}^{\circ} 35$.

3. Ramón Paz Ipuana en 1972 relataba el origen de los clanes de los Wayuu: fueron creados por Ma'leiwa, quien con el fin de crear un mundo ordenado decidió repartir a la humanidad en grupos. Entonces creó parejas de hombres y mujeres y les señaló un animal como símbolo: los epieyu con el buitre, los pushaina con el pécari, los Ipuana con el águila y así sucesivamente hasta completar treinta y seis clanes. Estas han ido variando algunos clanes han desaparecido otros se unieron a otros clanes con mayor fuerza económica a finales del XIX. Sin embargo se recogen las que refieren las autoridades para el momento que evidencia el desconocimiento e imprecisión de esta forma de organización. Así mismo no hay unificación en la gramática de los mismos y por ello se menciona tal como aparecen en la fuente, actualmente existen métodos de lectura y escritura en Wayuunaiki, lengua de los Wayuu, para ello se realizó entrevista a los lingüistas Wayuu, José Angel Fernández y Miguel Ángel Jusayu para contrastar los cambios. Sin embargo, se adecuaran en la medida de lo posible respetando la gramática del momento y se colocará entre paréntesis las ortografías actuales de los clanes que aún en la actualidad permanecen. 
del espacio geográfico del recorrido de estos grupos sociales ${ }^{4}:$ señalaba, los Zapuanas (Sapuwana), Cocinas y Cocinetas (Kusinas) eran los que habitaban las tierras orientales más próximas a los habitantes de la Provincia de Maracaibo: "Estos indios habitan las tierras altas de Cojoro, costa y caño de Neima, Jarira, Parauja, Aramachón, Gran Eneal y ciénagas inmediatas a Sinamaica, potreros y selvas de la parte del sur. Estos indios son muy pobres, viven de la rapiña y están en guerra siempre con las demás tribus". Por este motivo, son fuertes, arrojados y diestros en el manejo de las armas, por lo que los indios ricos solicitan sus servicios mercenarios y ellos se los prestan ocasionalmente, en las empresas militares, y los pagan del botín del enemigo, o con los animales de la propiedad de quien los ocupa.-Estas tribus, en todo el territorio en donde se hallan esparcidas, pueden levantar 3.000 hombres de armas" (Benites, 1975:30-32). (Véase MapaN ${ }^{2}$ 6.)

Menos numerosos son los Alpushianas (Aapüshanas) que recorrían la costa de Cojoro, El Salado y Güincúa (Wuinkua), el ganado les sirve de apoyo en sus modos de vida, aunque no era abundante "pero bueno y sus caballos tienen fama de corredores". (Idem: 32). Era vital para sus tráficos comerciales, la recolección de maderas de tinte que venden a los comerciantes que tocan el litoral oriental guajiro: "Las sierras inmediatas abundan en brasil y dividivi, como en Monte de Oca, lo que utilizan en el tráfico costeño". En cuanto a su poder describía como "aunque poco numerosos es temida, por su conocido valor y estrategia, y cuenta con unos 500 indios de armas". (Ibídem).

Los prósperos Hosayues (Jusayuu) aprovechaban las mejores condiciones ecológicas relativas a los cardonales y las humedales locales de la Serranía de Cojoro con alturas de 200 a 500 mts. que posibilitaban la abundancia de pastos: "Habitan el interior de la Teta de Cojoro. No tienen puerto de mar; pero son riquísimos en

4. Este personaje se destacó como Comandante Militar de las Guardias de Afuera e hizo su recorrido por la Guajira en varios viajes en 1874. Testimonio recogido por Marco Aurelio Vila. La Guajira en 1874. 


\section{EL TALLER DE LA HISTORIA 2}

ganados y bestias la riqueza allí está tan bien distribuida que es muy raro el indio que no posee algunos animales". Su fuerza era reconocida pues "son valientes y pueden poner unos 1.500 hombres sobre las armas”. ( Ibídem.)

Los Urianas (Ulianas) conformaban los grupos más numerosos en el sector noroccidental de la Península beneficiándose de las condiciones ecológicas de la Sierra de Macuira que posibilita la existencia del río Macuira: "Estos habitan las sierras y costas de Macuira, la parte más fértil de la península, bañada por un riachuelo que lleva el nombre del lugar, y hace excelentes las tierras de pancoger. Son ricos en ganado, mayor y menor de gran tamaño: también lo son de bestias de toda especie, pero su raza no es de las mejores. Esta tribu es pacífica y la más populosa, pueden poner sobre las armas 5.000 combatientes". Al interior de Macuira habitaban los Jarariyúes ( $\mathrm{Ja}$ yaliyuu) en las tierras más marginales, "poseen poca riqueza y pueden levantar 800 hombres de armas" (Ibídem).

Los Hipuanas (Iipuana) "habitaban las costas del norte que se dilata al Cabo de la Vela a Tairupo: en esta distancia se encuentra la famosa pesca de perlas." La riqueza de este grupo era considerada en relación con "sus ganados y bestias". Entre ellos "está tan bien distribuida como entre los hosayúes, a quienes son también iguales en fuerza, pues pueden presentar unos 1.500 indios armados, y son en la generalidad valientes". (Ibídem).

Los Purciarines (Pushaina) recorrían las costas del norte de la península: "de Macuira al Cabo de La Vela, en cuya extensión hay varios huertos: entre ellos los Portetes y la famosa Bahía Hon$\mathrm{da}$, en que se hace un comercio bastante activo, principalmente con Jamaica y Aruba. Sus riquezas consistían en ganado mayor y menor y en buenas bestias; son belicosos y pueden armar 1.200 indios. Los Jefes o indios principales, entre ellos tienen mucho orgullo, fundándole en que se dicen descendientes, por línea recta, de los antiguos arauras (abuelos) o caciques". (Ibídem). Estos indígenas atraviesan toda la Península para sus tráficos comerciales, 
llegando hasta el asentamiento criollo de las Guardias de Afuera donde traen frecuentemente su ganado, hamacas, perlas, carey, esponjas. La enumeración de estos productos revela que además de ser pastores seminómadas practican labores de pesquería, artesanado y recolección de perlas que constituyen sus actividades tradicionales ancestrales. Estas actividades eran realizadas también por los Hipuayúes (Eрiayuu), distribuyéndose preferentemente en el interior de la costa norte hasta cerca de Rio Hacha, comparativamente eran "iguales en riqueza a los hipuanas y a los hosayúes". Estos "Aunque no tienen costas, negocian con los buques extranjeros, por los puertos de La Vela y Bahía Honda: pero su mayor comercio con Río Hacha”. (Ibídem: 33).

Son muy variadas las estimaciones de la sociedad Wayuu que practicaba sus modos de vida tradicionales en la península de la Guajira. Algunas veces subestimada como la aportada por Codazzi en 1840 de sólo 18 individuos. Besson afirmaba que la población total de la Provincia de Maracaibo para 1839 había resultado "ser de 42.832 habitantes, entre los cuales figuraban 565 esclavos y 500 indios... en la Guajira se calculaban 9.000 indios que vivían cultivando maíz, frijoles, yuca y caña, criando ganado vacuno, caballar, mular y cabrío. Otros 9.000 se calculaban en la Guajira colombiana. Este dato fue recogido por Besson de Agustín Codazzi (1951,11:310-311). Benites aporta datos sobre la población de la Guajira para 1874, que igualmente diverge de otras estimaciones, según el autor la población Wayuu asciende a 38.000 habitantes repartidos en diversas parcialidades. De ellos 15.000 habitantes corresponden a indios varones útiles para el servicio de las armas, 3.750 habitantes corresponden a ancianos y niños no aptos para el servicio de las armas y 19.250 mujeres. Véase a continuación: 
54 EL TALLER DE LA HISTORIA 2

Cuadro Nro. 1

POBLACIÓN DEL GRUPO SOCIAL WAYUU APTOS Y NO APTOS

PARA LA GUERRA EN 1874

\begin{tabular}{|l|r|}
\hline URIANA & 5.000 \\
ZAPUANAS, COCINAS Y COCINETAS & 3.000 \\
HOSAYUES & 1.500 \\
HIPUANAS & 1.500 \\
HIPUAYÚES & 1.500 \\
PURCIARINAS & 1.200 \\
ALPUSIANAS & 500 \\
PARARIYÚES & 800 \\
Indios útiles al servicio de las armas & 15.000 \\
Ancianos y niños inaptos para. Id. id. & 3.750 \\
Mujeres & 19.250 \\
Total & 38.000 \\
\hline
\end{tabular}

Fuente: "Benites. Recuerdos de mis viajes a la Guajira". En: La Guajira en 1874 por Vila, 1874).

A pesar de las guerras y conflictos en el interior de la sociedad Wayuu, hay un factor que contribuyó a garantizar su existencia y número: sus modos de vida estaban basados en este período "en el seminomadismo pastoral" apoyado en la agricultura, recolección, caza y pesca. Desde muy temprano incorporó la actividad agropecuaria a su modo de vida y coexistió junto con las actividades tradicionales. Los pastores aprovecharon toda la extensión de su territorio para trasladarse junto con su familia y el ganado en busca de recursos que garantizaran su existencia. Cada una de las familias "agrupadas en pequeñas parcialidades es solidaria con las tribus enumeradas arriba y tiene su espacio de recorrido en sectores específicos de la guajira". (Cunill, 1987, II: 1210) Los grupos sociales más favorecidos por el pastoreo de ganado eran los que tenían acceso "a tierras más altas en la Serranía de Cojoro, Serranía de Jarara, Serranía de Macuira y Montes de Oca, o en los entornos 
de lagunas y ciénagas donde hay pasteaderos de jajato (Chloris radiata)". (Ibídem)

Las parcialidades, de acuerdo con lo que le ofrecía este vasto territorio, se veían más favorecidas por las riquezas naturales que ofrecían posibilidades de desarrollar actividad ganadera, disponer de fuentes de agua o estar ubicadas en la costa en cuanto podían realizar un provechoso contrabando; peculiaridades que les permitía especializarse en determinadas actividades económicas, complementadas con la caza, pesca, recolección de ñutos, conchas y perlas, cría de ganado menor y actividades agrícolas para garantizar la dieta básica de la comunidad. (Ibídem). Véase cuadro anexo Nro. 1 y 2 que manifiesta la distribución de las parcialidades, su número, lugar de residencia, carácter y ocupaciones.

Con respecto a estos cuadros conviene realizar algunas reflexiones, se tomará en cuenta el análisis del cuadro anexo $\mathrm{N}^{\circ} 1$ por ser la relación oficial que llega a la Secretaría del Ministerio de Interior y Justicia. La información fue recogida por las autoridades de las Guardias de Afuera, fortificación militar que regulaba el comercio Wayuu par 1850, para este momento la población era según el cuadro 90.379 habitantes, información que no se corresponde con la de Benites en 1874 de 38.000 individuos. En un artículo titulado "Apuntes Guajiros" realizado por Juan Macpherson (hijo) refiere que en el año 1846, "se calculaba en 90.000 los habitantes de toda la península incluyendo los indios cocinas de Cushe que viven en las tierras interiores, lindando con la Sierra de Perijá" en la Provincia de Maracaibo y con la de Santa Marta en el del Magdalena colombiano Para 1877 se calculaban $100.000^{5}$. Aunque los datos del cuadro son imprecisos, se intuye el incremento de población el cual obedeció a varios factores como la longevidad en el Wayuu, el matrimonio a inicios de la pubertad de la adolescente, la poligamia en la cual se puede casar con dos o más mujeres al mismo tiempo, el fortalecimiento de las actividades económicas que

5. Artículo titulado: “Apuntes Goajiros”. En: La Opinión Nacional, Caracas, 7 de agosto de $1877, \mathrm{~N}^{\circ} 2.473$. 
permitió diversificar sus modos de vida tradicionales aumentar la producción y consumo para garantizar su existencia.

Otro aspecto que se destaca en la relación del cuadro anexo $\mathrm{N}^{\circ} 1$, que refiere las parcialidades de la guajira, eran los lugares en que residían; la mayoría vivía en su territorio tradicional y se desplazaba desde grandes distancias como Bahía Honda, Macuira, Pórtete entre otras. Refiere su carácter en el cual lá mayoría era "belicosos", "guerreros", "pacíficos unos y belicosos otros" para catalogarlos de esa manera tenía que conocer la capacidad de respuesta de cada una, su acción bélica, y la vinculación con las parcialidades amigas. En ocupaciones "ordinarias" también distingue entre "ladrones y criadores". Aparentemente los Wayuu y los Cocinas o Cocinetas influyeron en esa distinción, sin embargo especifica que los "Cocinetas" eran de carácter belicoso y su origen de Macuira y Pozones se dedican a la cría y a la pesca de perlas con un total de 14.800 .

\section{GRUPOS SOCIALES EN LA PENÍNSULA DE LA GUAJIRA: WAYUU Y COCINAS. PUGNAS Y CONFLICTOS}

Los rasgos descritos anteriormente permiten, de alguna manera, explicar en cierta medida las fricciones grupales. Se puede afirmar que existían diferencias socioeconómicas entre cada una de las parcialidades; en un Comunicado titulado "Goajira", de 1858, se señalaba que para la mayor comprensión de la comunidad "deberemos hacer la clasificación social que ellos establecen y que denominaremos para más fácil inteligencia nobles y plebeyos, aquellos son los que ejercen la industria pecuaria quienes se denominan ricos o guarires los otros son cultivadores pero en pequeña escala; y eso de sólo maíz cuya cosecha casi siempre la pierden por la escasez de las lluvias y la falta de aguas corrientes para fertilizar el terreno"6.

6. En: Diario de Avisos y Semanario de las Provincias, Caracas 27 de febrero de $1858, N^{\circ}$ 35. 
La participación de las parcialidades en el comercio tuvo un fuerte impacto en su estructura social. Ello reforzó el desarrollo de una jerarquía fundada en el prestigio de riqueza individual. Los Wayuu distinguían entre el parentesco transmitido por la carne (eirruku) - matrilineal - y el parentesco transmitido por la sangre - patrilineal- los lazos matemos o uterinos se consideran más fuertes que los patrilineos y las subdivisiones de los Wayuu en clanes o parcialidades corresponden al matrilinaje. En el ámbito colectivo, la parcialidad asegura la estabilidad económica, la protección permanente y su reproducción. De esta manera la familia y el matrilinaje se establecen como las fuerzas omnipotentes en la vida de cada hijo perteneciente al gmpo. (Cfr. Saler, 1977:6-8)

Según otros testimonios de la época, los "indios pobres" eran los cocinas; versión ratificada por Simons Fredd en $1880^{7}$, a su modo de ver era "una horda de salteadores que han sido expulsados de sus parcialidades por pendencieros, asesinos y ladrones, y obligados, por tal razón al pillaje para ganar la vida... se reúnen en grupos más o menos numerosos con jefe reconocidos" (Jahn, 1973:160). A finales de esta década el cónsul norteamericano en Maracaibo E. H. Plumacher ${ }^{8}$ corroboraba estas diferencias socioeconómicas de la comunidad Wayuu:

Los indios tienen sus peculiaridades específicas de la misma manera que los blancos. Aquellos de la costa componen la clase inferior estando mal alimentados, mal vestidos y propietarios de pocas reses que constituye la riqueza guajira. Andan para arriba y para abajo en la costa sin tener ningún pueblo organizado, mientras que en el interior de la Provincia hay tribus poderosas, ricas en ganado, caballos, burros y ovejas, quienes han vivido durante generaciones en los mismos pueblos. Están bien vestidos, bien armados y tienen mucho orgullo de raza, rehusando bajo ninguna circunstancia ne-

7. Según la apreciación de Alfredo Jahn, Simons era considerado como el viajero que manejaba mayor información sobre los habitantes de la península a finales de siglo. (1973:160).

8. Cónsul norteamericano que describió al Zulia a finales de siglo. 1877-1890. Memoir. Tennessee State Library and Archives.Nashville. Manuscript. Microfilm. 


\section{EL TALLER DE LA HISTORIA 2}

gociar con los hijos, cosa que los indios de la costa siempre están dispuestos a vender a su propia carne y sangre siempre que puedan hacer un buen negocio. (1877-1890).

En el siglo XIX, se designaba con el nombre de Kusinas o Cocinas a un grupo específico de indígenas que vivían en un territorio de la Península de la Guajira en una región llamada "Sierra de los Cocinas" o "Sierra Kusina" (Perrin, 1989: 43). Es preciso analizar la importancia de este grupo en la península por las implicaciones en los enfrentamientos y luchas con los Wayuu y los habitantes de Sinamaica. Se puede considerar que en lugares que conviven grupos étnicos diversos "el proceso de intercambio cultural se acentúa, predominando uno o conformándose tres o cuatro cosmovisiones del mundo en uno solo, es decir, se presenta un proceso de etnogénesis"9. (Bonilla, y otros, 1996:14).

Para algunos, se trataba de individuos desterrados de la sociedad guajira en razón de los crímenes y otras fechorías, que se habrían organizado en bandas malhechoras que saqueaban y que robaban en toda ocasión a los Wayuu, o a los que estaban de paso "contando con bastante fuerza se arrojan de improviso sobre partidas menos numerosas e indefensas arrebatándoles cuanto poseen". Jahn por su parte afirma que "el guajiro que tenga algún pariente entre ellos, cuenta con seguridad, por parte de la pequeña banda, en que éste se halla afianzada. Los guajiros que trafican con ellos a menudo logra que les sean devueltas las reses que les fueron robadas.'(Jahn, 1973:159-160). Para otros, los Kusinas formaban parte de un grupo realmente diferente, enclavado en la guajira. (Perrin, 1989: 43). Los cocinas parecen haber desarrollado una estructura social de cazadores y recolectores. (Purdi, 1987:134). Codazzi expresa que "los cocinas están sometidos a los guajiros hablan un dialecto de la lengua de estos, lo mismo que los sabriles o los cucinetas". (1940:17).

9. La etnogénesis se aplica a la construcción de la identidad de grupo y a la revitalización o persistencia de rasgos culturales caracterizadores de un grupo social sometido a procesos de cambio radical y rápido. También se refiere a un sistema étnico nuevo que emerge de la amalgama de otros grupos. 
A pesar de las diferentes posiciones en la distinción de los Wayuu y cocinas, las fuentes de la época permiten identificar dos grupos claramente diferenciados, por lo que se hizo necesario hacer las precisiones pertinentes. Los primeros eran "propietarios de más o menos valores, y se envanecen de ser ricos y nobles"; así mismo "gozan de cierta comodidad relativa a su condición", los segundos "nada poseen sino el área que ocupa, y viven de la caza pesca y el hurto" ya que "apenas adquieren con que alimentarse escasamente, y a veces sufren hambres compasibles que los obligan a separarse de sus propios hijos". Estos a su vez eran "vilipendiados" por los Wayuu con las designaciones de "perros y zorros". Era de tal forma su rechazo que cuando un Wayuu de los "nobles" mataba a un cocina "goza de impunidad porque el muerto es un perro, un animal". Como veremos más adelante los cocinas al verse "despreciados y ofendidos, y sin poder vindicar su ultraje" profesaban un "odio concentrado contra todos los individuos que no son de su casta, y procuren hacerles el mal a hurtadillas, alevosamente con traición" ${ }^{\prime 10}$.

Las autoridades y habitantes de Sinamaica, fundamentados en la visión que tenían de los cocinas de "belicosos", los consideraba su común enemigo, los informes referían que el carácter de esta parcialidad les distinguía de “...desconocer enteramente aún las ideas más vulgares de toda normal política, ni religiosa y que regularmente hablando, estos han subsistido a las virtudes sociales, los más insignes crímenes condenados por toda sociedad humana" ".

En este sentido, las mismas autoridades distinguían los grupos belicosos y las parcialidades pacíficas de la siguiente manera:

Mucho me intereso que en esa Villa quede a cubierto de los nuevos atentados de los salvajes. Bien conozco que la generalidad de las

10. Artículo titulado: Reseña de los usos y costumbre de los indígenas goajiros e indicaciones para su reducción y civilización en 1874. En: El Zulia Ilustrado. 30 de noviembre de $1890 . \mathrm{N}^{\circ} 24$.

11. Comunicación del Juez Parroquial $2^{\circ}$ José Manuel González enviada al Señor Gobernador Jefe Superior de la Provincia. Archivo Histórico del Estado Zulia (en adelante A.H.Z.) 1837, Caja $\mathrm{N}^{\circ} 2$, Carpeta $\mathrm{N}^{\circ} 20$. 


\section{EL TALLER DE LA HISTORIA 2}

parcialidades guajiras mantienen útiles relaciones con esa parroquia, y que aún guardan ciertos respetos a las personas y a las propiedades, pero al mismo tiempo deduzco por los informes de $\mathrm{u}$. y de otras personas que hay una horda de indios que está considerada como sumamente perjudicial, por sus propensiones al robo y al asesinato, en términos que aún el resto de los guajiros los miran con odio y enemistad ${ }^{12}$.

Es cierto que los Wayuu no dejaban de temerlos, y que "no se atreven a pasar por su territorio sino en número suficiente para defender sus rebaños y haciendas". El gobierno dictaba las medidas para favorecer las relaciones mercantiles con la finalidad de lograr simultáneamente la "civilización" de los Wayuu, consideraban que era la única posibilidad de lograr una comunicación con los indígenas. En la práctica se observaban pocos logros para el Estado venezolano, se mantenían las acometidas de los Cocinas y Wayuu agraviados por los vecinos y autoridades de Sinamaica, situación que afectaba el comercio y dificultaba el cumplimiento de las funciones de estas últimas. Cabe destacar que, el gobierno sólo distinguía en la península dos grupos: el de los "Guajiros" y el de los "Cocinas". La opinión pública de la época instaba a "dictar dos reglamentos: uno especial para los guajiros amantes de nuestro pueblo; y otro para los nombrados cocinetas, inclinados por lo general al robo y a la matanza" Señalaba que los mismos "deben destinarse a trabajar bajo la inspección de hombres que vigilen y observen su conducta, proporcionándole lo que necesiten para que se olviden, si es posible de la inveterada inclinación que tienen a robar" $" 13$.

Según el reporte del Ministerio de Fomento, elaborado en 1874, ampliado por los editores de El Zulia Ilustrado en 1890, se deduce que los Wayuu constituían una sociedad descentralizada en la cual no había un "jefe general”. Actuaban, por ello, en forma autónoma y diversa, era la unidad familiar lo que le daba cohesión al grupo

12. Comunicación del Señor Gobernador de la Provincia al Sr. Alcalde Parroquial de Sinamaica en ejercicio. A.H.Z. 1837, Caja $\mathrm{N}^{\circ} 2$.

13. La Mariposa, Maracaibo, 25 de junio de 1842. 
social; aparentemente se veían disgregados debido a que los miembros de la parcialidad sólo se comportaban en forma coherente ante las dificultades o decisiones a tomar. También "se subdividen en rancherías o familias, extrañas a toda forma de Gobierno". La organización política estaba determinada por un Jefe, autoridad de cada una, quien era un "individuo que descuella en la parcialidad por su valor y pericia y más principalmente por su riqueza en ganados y bestias; a virtud de cuyos recursos alcanza influencias y prestigio para juntar los guerreros y conducirlos a las incursiones y asaltos sobre sus contrarios". A lo largo de estos años figuraban "algunas mujeres que han obtenido el rango de jefes como las dos indias Rosas y lo han desempeñado honoríficamente". (193).

\section{LA LEY CONSUETUDINARIA WAYUU: FACTOR DE INTEGRACIÓN Y DE COHESIÓN SOCIAL ANTE EL ESTADO VENEZOLANO}

Según las fuentes orales, los Wayuu pagaban las ofensas serias, tales como homicidio y daños corporales graves, sólo con sangre. En tiempos anteriores, "la vida se pagaba con una vida, una herida con una herida". Pero con la adquisición de ganado doméstico, traído por los europeos, los informantes alegaron que el ganado "vacuno, caballos, muías, asnos, ovejos y chivos", así como también "ciertos tipos de collares y otros bienes de valor material fueron ampliamente aceptados como forma de desagravio" (Saler, 1986:54). En este sentido, cabe preguntarse: ¿Qué es la ley para los indígenas? Reimán expresa por su parte que:

...la mayoría considera como proverbio relativo al camaleón, que cambia de aspecto en cada lugar y sólo sirve a quienes ya conocen sus mañas. Cualquiera que sea la apariencia de la ley dentro de la sociedad determinada tiene que mirar a otras direcciones para no crear condiciones propicias a la tiranía. Todas las sociedades tienen un sistema definido de instituciones, la ley occidental crea injusticias destruyendo los derechos tribales. (1975:66) 


\section{EL TALLER DE LA HISTORIA 2}

El trato entre Wayuu y al ijunas estaba marcado por permanentes tensiones que llevaban con frecuencia a los indígenas a enfrentarlos en forma violenta con el propósito de defender su soberanía, integridad y negocios. En estas contiendas, levantamientos, tropelías o incursiones, los Wayuu hacían valer sus propias formas de control social o leyes consuetudinarias. Al considerar dichas leyes, podemos entender que los Wayuu han utilizado la violencia solamente cuando un acuerdo se incumple. Cuando se quebranta una norma, no se acude a la violencia directamente; se procede a investigar las responsabilidades en el hecho; luego, se envía al palabrero o putchipü; y en último caso, si no hay acuerdo, se recurre al enfrentamiento armado. Sus creencias sobre la reciprocidad estipulan que cuando alguien violaba los derechos cívicos de un miembro de un clan materno, todos los miembros de dicho clan quedaban involucrados en una batalla con el delincuente y su parcialidad.

La explicación más lógica tiene que ver con el principio que regulaba esta sociedad, por la cual no se aceptaba un negocio malo o el incumplimiento de un convenio. Es necesario aclarar aquí las razones por las que pelea el Wayuu que se resumen en tres situaciones que serán ampliadas en los dos últimos capítulos: una era por el control de un territorio y de los recursos presentes en él por parte de sus habitantes que se complejizaba por las diferencias socioeconómicas descritas anteriormente y la preponderancia política en un territorio determinado que permitía el aprovechamiento y hegemonía por parte de los jefes de cada grupo; otra era el quebrantamiento de normas sociales como el homicidio, el hurto de ganado, disputa por fuentes de agua, que requerían indemnización (Cfr. Reclus, 1936: 121-128).

Benites Rafael en su viaje a la Guajira recogió aspectos referidos a la ley Wayuu:

La venganza, en el indígena, a más de instinto natural, es un precepto de sus leyes tradicionales, que la impone al individuo y a toda la familia o parcialidad, por muerte violenta, derramamiento de sangre, injuria de hecho u ofensa a la dignidad personal que 
produzca ridículo, contra el perpetrador y los suyos, sin tiempo de prescripción, ni reprobación de medios; pero cuando se entablan negociaciones y se alcanza que el ofensor, u ofensores, den pública satisfacción de la ofensa, haciendo pagamento de daños y perjuicios con un número de animales y efectos, que estipulan las partes interesadas, se depone el encono y se restablecen las buenas relaciones. (1975:26)

La norma también establecía que el líder de la acción contra los alijuna debía indemnizar los daños materiales y las pérdidas humanas, considerados agravios cometidos contra los familiares $\mathrm{u}$ otras parcialidades. La misma regla se aplicaba hacia quienes no eran Wayuu. Las autoridades debían, de alguna manera, cancelar este "daño" o "mala acción — aainjalaa mmojulu'ulu_ " mediante contratos concertados entre las partes, quienes acordaban el modo de saldar la deuda. Es necesario saber que los Wayuu concebían a las personas "como individuos, con los derechos que tienen como seres autónomos”. Pero, a la vez, su estimación del valor social de un individuo se basa, a menudo, hasta cierto punto en "sus evaluaciones sobre el grupo de parientes con el cual identifican a ese individuo". Es por ello que la indemnización de los agravios evalúa tanto cuantitativamente como cualitativamente, (sujutu Wayuu: valor de la persona); en esta última, se toma en consideración "no sólo la categoría de la ofensa, sino también al mérito, valor, precio de la persona, cuya integridad violada es la razón explícita para pedir compensación (Sahler, 1986: 56).

Sólo con estos acuerdos de compensación se lograba cierta paz entre las parcialidades y las autoridades blancas; aspecto asimilado por el Comandante Juan Macpherson quien desde 1830 legitimó esta ley al mediar en los conflictos y cancelar las "deudas del Estado" con los indígenas. Este Comandante "hizo cuanto pudo por inspirarles confianza y afecto y moralizó el comercio, vigilando con celoso interés que los indios no fueran estafados ni maltratados". Los testimonios añadían que él utilizó como estrategia para ganarse la confianza, el regalo mediante "objetos de poco valor, pero del gusto de ellos, como puñales, navajas, tabacos y tragos de 


\section{EL TALLER DE LA HISTORIA 2}

aguardiente también, con tasa, para evitar la embriaguez y con ella los excesos "14.

Esta autoridad fue clave en la relación entre los habitantes de la localidad y el gobierno venezolano. Estuvo en el cargo de manera intermitente desde inicios de la República hasta el período de Guzmán Blanco. Alfredo Jahn afirma, según la investigación realizada, que "el nuevo Jefe trató de borrar el mal recuerdo que los indios guardaban de los blancos y moralizó notablemente el trato con los indígenas, haciendo que estos gozaran de garantías en su vida e intereses y que en el comercio que hacían con los vecinos no fuesen engañados ni perjudicados: trató, en fin, de atraerlos por todos los medios posibles". (1973: 138-139). Para lograrlo, Macpherson se alió con algunos líderes Wayuu quienes fungían de intérpretes, informantes e intermediarios con los otros grupos.

Aprovechó lo que establecía la norma consuetudinaria Wayuu que consideraba "la ley tradicional del pago de la sangre", en este sentido: "cualquier homicida debe responder del precio de la que hace derramar" porque era considerada sagrada. El que hería o mataba a un Wayuu, fuera o no de la comunidad, y no cumplía con lo establecido por la ley, era "compelido a viva fuerza por la parcialidad del agredido, cuando rehúsa o evade el pago, no sólo en su persona y bienes si no que también en los demás miembros de la asociación a que pertenecen". De esta manera, la ley ancestral "sirve de freno, economizando vidas y propiedades por temor de incurrir en el castigo, comprometiendo además a los suyos, cuando el intento es personal"; al parecer de los habitantes de la Provincia su principio de autoridad "era débil y limitado en su acción", no obstante, llegó a regular las relaciones interclánicas, y de las parcialidades con los habitantes de la Provincia. (Ibidem: 193).

Ante la complejidad de este código moral, las autoridades locales permanecieron, en la medida de lo posible, ajenas y trataban

14. Artículo titulado: "Reseña de los usos y costumbres de los indígenas goajiros e indicaciones para su reducción y civilización”. En: El Zulia Ilustrado, Maracaibo, 30 de noviembre de 1890: 192, $\mathrm{N}^{\circ} 24$. 
de no involucrarse en los problemas entre las parcialidades. La Comandancia de la Línea se liberaba de toda responsabilidad y por el contrario sacaba provecho de las diferencias internas que impidieron la alianza de los Wayuu en contra de los asentamientos blancos. Conscientes de esta realidad afirmaban en 1858 que:

Se miran recíprocamente con odio, sirviendo esto afortunadamente de escudo o defensa a la Parroquia de Sinamaica que con 60 individuos de guarnición, y un pequeño fortín no podría resistir el choque de 35 o 40 hombres robustos y belicosos que estando unidos entre si podrían organizarse y no solo destruir aquella población, sino la de los campos limítrofes con ella en el Cantón Maracaibo, y quizás amenazar hasta la misma ciudad de aquel nombre's.

Cuando los sucesos ocurrían dentro de las Guardias de Afuera o Línea de Sinamaica, las autoridades intervenían disparando cañones o actuaban directamente para evitar que trascendiese la pelea entre parcialidades, sobre todo en el momento de comerciar. Tal es el caso del indio Mature, quien se presentó con tres de sus parciales a comerciar y fue atacado por sus contrarios de los cuales resultó uno muerto y uno herido. Es por ello que "iban a trabar una pelea sangrienta por lo que tuvieron que intervenir decomisándoles sus bestias" $"$. Este enfrentamiento, según las declaraciones de Mature, revelaron la enemistad con la parcialidad agresora:

...no quiso al principio contestar el fuego (sin) refugiarse con su atajo al monte para que dicho Comandante no se pusiera bravo y tenerlo en su favor: pero al sortear una raya que le dispararon, se salió de la silla, y acometido por muchos en su caída le fue forzoso defenderse, y para con los suyos a vender caras sus vidas creyéndose entonces sin escape pues ni aún podía correr por el arenal con las cotizas de monte que traía que a nuestra llegada huyendo sus

15. Comunicado titulado: "Goajira". En: Diario de Avisos y Semanario de las Provincias, Caracas, 27 de febrero de $1858, \mathrm{~N}^{\circ} 35$.

16. Comunicación del Comandante de la Línea de Sinamaica Rafael Benites enviada al Gobernador de la Provincia de 20 de septiembre de 1845. A.H.Z. 1846, t. 27, leg. 25. 
enemigos dejaron de atacarle, y el celo de la defensa obligaban, y el (celo) de la defensa a que le obligaban, y se nos presentó al punto, porque nada tiene que temer a los españoles, de quienes siempre ha sido amigo, y contra quienes nadie puede hacerle la más pequeña acusación ${ }^{17}$.

Una peculiaridad de esta declaración, al igual que en otros documentos, es que los "indios amigos" reiteraban su amistad a los "españoles" como todavía se les designaba a los vecinos y autoridades de Sinamaica. Por esta solidaridad, la autoridad militar se veía en la obligación de actuar filantrópicamente "sin imponer un castigo serio a la falta cometida en nuestro territorio" en virtud de "la ignorancia de los que lo han cometido sin intención de ofendemos, sólo siguiendo sus costumbres salvajes, y que de otro modo hubiera sido alejar por mucho tiempo, como ha ocurrido en idénticas ocasiones". En el fondo, se estaban defendiendo intereses particulares en cuanto participaban del comercio ${ }^{18}$.

Estas fuentes revelan la especificidad en el comportamiento del Wayuu lo que permite comprender su cultura y normas consuetudinarias. Sin embargo, en ese momento muchas de las actitudes del Wayuu eran desconocidas y no aceptadas por el alijuna, por ejemplo en comunicación de Juez $2^{\circ}$ de Paz en Ejercicio, dirigida al Sr. Gobernador en Ejercicio, le manifestaba que se presentaron varios vecinos a exponer la queja de que el Comandante de las Guardias de Afuera, el Subteniente Cruz Jiménez, había dejado pasar a comerciar unos indígenas que portaban armas. Dicho Subteniente les intimó "a que dejasen las armas afuera" y ellos se "resistieron diciéndoles que no las dejaban porque tenían enemigos"19.

Además, las fricciones de los marabinos con cada parcialidad se agudizaban en momentos de realizar las actividades comercia-

17. Ibídem.

18. Ibídem.

19. A.H.Z. 1841, tomo 14, legajo 15. 
les. Cada una de ellas vendían sus productos y artesanías en Sinamaica o con Maracaibo, a través de la fortificación denominada Guardias de Afuera. Con frecuencia, trataban de sacar mayor provecho de la transacción; sin embargo, los vivaces comerciantes Wayuu no eran fácilmente engañados. Su respuesta ante un negocio insatisfecho era tomar la propiedad de los otros, que ante su ley ahora le pertenecían; y en caso extremo, atacar a los nuevos enemigos, quienes habían faltado a su honor; acciones que llevaron a los blancos a afirmar que los indígenas eran ladrones y $\operatorname{asesinos}^{20}$. En realidad se estaban enfrentando dos tipos de culturas, el Wayuu se sentía con derecho de cobrar el agravio recibido.

\subsection{LA APLICACIÓN DEL PRINCIPIO DE JUSTICIA WAYUU Y LAS MEDIDAS DEL ESTADO VENEZOLANO}

Se puede afirmar que la relación entre las autoridades y alijunas de la localidad de Sinamaica con los indígenas, era bastante compleja. De allí que fuera necesaria la adecuación de ambas sociedades para poder mantener la vinculación económica. Los resultados de las leyes creadas fueron, en un primer momento, favorables para ambos; sin embargo, los abusos cometidos de parte y parte obligaron, en ocasiones, a la instrumentación de medidas más drásticas.

En este punto, vamos a referir las situaciones que se presentaban en los casos de justicia entre los mismos indígenas y con los alijunas. Es necesario examinar algunos ejemplos de disputas, para

20. Manuel Matos Romero, según los testimonios orales, recoge la institución del aparto en la Guajira este era el "botín que el vencedor toma al vencido". Es jurídicamente diferente del robo o hurto en la cual el Wayuu da asalto a propiedades del agresor o enemigo y se lleva la cantidad de animales que considera proporcional al pago de la indemnización que cree que se le debe. Lo demás que haya, lo deja, porque con lo obtenido se considera indemnizado. El aparto quizás evitó entre las parcialidades derramamientos de sangre y guerras, pero en el caso de los Vecinos de Sinamaica trajo muchas molestias para las autoridades quienes no comprendieron esta forma de resarcimiento según sus costumbres. Para mayor información consúltese sus obras Wñiasus Woumain. La sedienta Guajira y Derecho Civil y Penal Guajiro el putchipú o abogado guajiro. 
damos cuenta de la diversidad de caminos que puede tomar una contramedida para hacer efectiva una ley y mantener el orden moral que la fundamenta. Reiman afirma que "el aborigen enredado en un juicio, más que nada, con un código procesal inhumano. En las regiones indígenas los mayores conflictos se suscitan entre las costumbres y la ley escrita. Las estructuras formalistas de la legislación no se compadecen con la realidad". (1975: 67). Los problemas eran de diversa índole tales como homicidio, robo de ganado o propiedades, problemas de adulterio, responsables de invasiones entre otros. Hay expedientes judiciales en los cuales se hacía seguimiento de casos a indígenas por estos acontecimientos.

Por lo que puede observarse, esta situación refleja distintas concepciones de la ley, en la cual el poder judicial tenía que dirimir los problemas que se presentaban entre los gmpos en fricción. Al respecto Codazzi afirmaba que una de las razones más difíciles era solucionar casos de justicia entre los indígenas:

...cada cual procuraba con sus armas, la astucia o el veneno, vengarse de las ofensas recibidas. Hombres desnudos, sin tierras propias, siendo todas ellas del primer ocupante, ríos sin número que les proporcionaban pescado en abundancia, selvas inmensas que les brindaban con toda especie de cacería, difícilmente daba lugar a que hubiese pleito entre aquellas gentes, y cuando ocurría lo decidían por la fuerza. Los caciques o capitanes podían cuando más conciliar la paz; pero no tenían autoridad para castigar. Si uno era muerto por los parientes vengaban matando la sangre al que mató, o en caso de no encontrarle, en cualquiera de su familia o de su tribu ejercían venganza, costumbre que aún existe entre los indígenas independientes y que ellos llaman vengar la sangre. (1960:290)

Las leyes de la República dirigidas a la "Reducción y Civilización" regularon los casos de justicia, sin embargo, suscitó muchas controversias para los vecinos de Sinamaica quienes no estaban de acuerdo con el hecho de no poder acometer directamente a los indígenas; el artículo $5^{\mathrm{O}}$ del "Decreto Ejecutivo sobre Reducción y Civilización de Indígenas de 1840" había establecido la prohibición de que los particulares "tomen satisfacción de los agravios y ofensas dentro ni fuera del territorio de la Guajira" y adver- 
tía "el que infringiere esta prohibición, será tan culpable como el que pretende entre los venezolanos prescindir de la jurisdicción pública para hacerse la justicia por su mano". (Armellada, 1977:7576) En el artículo titulado "Cuatro palabras al decreto sobre Reducción y Civilización de Indígenas", el articulista comentaba que esta disposición:

Es irrealizable, y nótese ya que es también perjudicial, y aún ataca al derecho natural y civil que tiene todo hombre de defenderse cuando amenaza su existencia. En efecto se prohíbe a los habitantes de Sinamaica que tomen por si a satisfacción de los agravios y ofensas que les irroguen los goajiros dentro ni fuera de su territorio: de manera que el venezolano, o experimenta el rigor de nuestras leyes, o se resuelve a que circule por sus venas el letal veneno de las rayas de los guajiros, cuando por desgracia tenga alguna querella con cualquiera de ellos ${ }^{21}$.

Así mismo, el decreto dictaminaba que el Gobierno y demás instancias "estarán siempre pronto a oír sus quejas y hacerles justicia", también regulaba los agravios cometidos por algunos en caso de cometer "uno o más hechos contra las personas, el honor y las propiedades de los habitantes de la Provincia", debería "el jefe o la parcialidad a que corresponda el culpable hacer entrega de este a las autoridades que le reclamen y deban juzgarlo conforme a las leyes o bien hacerles pagar la competente indemnización, sino hubiese materia de pena corporal". Al acogerse a la regla y entregarse a la justicia, la comunidad "quedará libre de responder por los hechos de sus miembros particulares", de lo contrario los familiares serían retenidos como rehenes, conforme a la "costumbre que ellos observan entre sí mismos y con nosotros" (Armellada, 1977: 76).

El articulista ampliaba los alcances del decreto en cuanto se les prohibía a los habitantes "ahora repeler como siempre lo han hecho las invasiones robos y matanzas de los guajiros", manifesta- 


\section{EL TALLER DE LA HISTORIA 2}

ban que esto sería altamente peijudicial a los intereses de la localidad: "el sólo sería suficiente para abandonar Sinamaica y dejarle el poder de los indios..."22. En relación con la disposición, expresaba "mayores son las dificultades, que no ha tenido presente la risueña teoría del Poder Ejecutivo" que prescribía la potestad del jefe de la parcialidad de hacer entrega del "individuo que haya atacado el honor o las propiedades de los habitantes de la Provincia como si tuviéramos poder sobre ellos" agregaban: que los indígenas no iban a ser capaces de "conocer el bien de esta medida" que realmente lo produciría "si estos ligeros halagos para atraerlos a la civilización, no los creyéramos inferiores para oponerse al poder irresistible del hábito, educación y ejemplo". Concluía que "los inconvenientes notados en el decreto que impugnamos desaparecerían, si hubiera dinero con que pagar muchas autoridades, y tropas que vengase los agravios de los venezolanos" $" 23$.

Por otro lado, el articulista no destacó los perjuicios para la comunidad Wayuu en el caso de que un indígena realizare daños o agravios, toda la parcialidad quedaba comprometida "si es llegado el caso de tomar represalias y esperar la competente autorización para hacer uso de este derecho" este consistió en aprehender

...uno o más individuos de la misma parcialidad, que sirvan como rehenes, ocupando aquella parte de sus bienes, que basten a cubrir la indemnización competente, haciendo un escrupuloso inventario y conservándolos en depósito mientras se hace una nueva demanda a la parcialidad o tribu comprometida y se vea si se obstina en negarse a la reparación, en cuyo caso se acordarán por el Poder Ejecutivo las demás medidas convenientes (Armellada, 1977:76-77).

Este derecho de represalia por parte del Estado venezolano fue ejercido en muchos casos para la reparación de los daños causados por los Wayuu. Reiman afirma que "cuando se ha manifestado el interés de hacer censo o promoción de desarrollo aborigen, de inmediato surge la reacción disfrazando la discriminación con 
declaraciones de impregnadas de igualdad ante la ley; si, las constituciones establecen igualdad ante la ley, pero eso no remedia el problema. (1975: 70).

Antes de la ley de 22 de octubre de 1842, los indígenas que eran sometidos a procesos judiciales, se consultaba las leyes de Indias para las referidas sentencias. ${ }^{24}$ En el caso de adulterio, podemos referir, el sumario criminal seguido a Manuel Rivera vecino de la Parroquia de Sinamaica por el delito de adulterio cometido con la mujer de un indígena Wayuu nombrado Jusayú o Amigo $^{25}$. Para este momento, las leyes regulaban las dificultades cri-

24. Podemos referir el caso particular de la Conmutación de la pena de muerte impuesta a los indígenas Wayuu Negrito y Amiguito - Campeche y Felipe respectivamente- por la muerte del indígena Piachito quien era peón de Rafael León. La sentencia de la Primera Instancia era "un asesinato cometido con premeditación, por una porción de hombres armados, contra un individuo inerme, que sólo procuraba evitar la muerte". Las razones alegadas por el defensor de los encausados "consiste en aparecer probado, que los indios agresores viven en una tribu separada de la población, llevando una vida salvaje." Las autoridades para este momento sabían que "ellos — Wayuu - se creen autorizados para vengarse privadamente entre sí, razón por la cual mataron a Piachito, diciendo que había rayado a una guaricha - Francisca Paula Díaz - hermana de Felipe -Amiguito- La Corte sin embargo, no encontraba "exceptuados de la pena legal ordinaria por homicidio, a los que viven en despoblado o carecen de civilización" por el contrario "la ley veintiuna, título primero, partida primera, declara no excusados de recibir la pena impuesta por las leyes, en los casos como el presente a los pastores que andan con los guajiros en los montes o en los yermos" No quedaban exceptuados los indígenas Negrito y Amiguito los cuales vivían en la Parroquia de Sinamaica y tenían que someterse a las leyes para ese entonces vigentes. Por ello, "obligados los tribunales a aplicar literalmente la ley en los casos ocurridos y estándoles prohibido por la quince, título octavo, libro séptimo Recopilación de Indias, moderar las penas legales; y por la séptima, título cuarenta, libro doce Novísima Recopilación, dejarles de imponer con exactitud y escrupulosidad, inclinándose a una remisión arbitraria por nimia indulgencia no pudo el Juez inferior, como no puede ahora la corte dejar de aplicar a un homicidio con circunstancias muy agravantes." Así mismo, "la ley segunda, título veintiuno, libro doce de la novísima Recopilación que impone la pena capital.” En la sentencia se acudió a la excepción que la misma ley estipulaba, por lo que se ordenó suspender la ejecución de la pena de último suplicio. Y se apegaron a la atribución vigésima primera de la Constitución de 1830, artículo 117 para conmutar la pena de muerte. Tomando en consideración las justas razones que los movía. 11 de Junio de 1839. A.G.N: 1840, tomo CCVIII. Exp. 52. Folio 347. (Subrayado de la autora)

25. En esta situación era un ciudadano de Sinamaica quien agraviaba a un indígena. Las autoridades ordenaban las medidas "para que no se les dé mal tratamiento a los indios 


\section{EL TALLER DE LA HISTORIA 2}

mínales mediante la ley de 22 de Octubre de 1842 , en cuanto a la Guajira se trataba especialmente de:

...mantener en todo su rigor la sujeción que se hallan constituidos los Vecinos de Sinamaica de reparar los prejuicios que se les irroguen en sus personas, bienes y honor, hasta sufrir en caso necesario el condigno castigo: todo con el objeto de que se abstengan de cometer hechos hostiles contra los mismos vecinos en vindicación de sus propias ofensas, que ocasionan la interrupción de la buena inteligencia y armonía que tanto interesa el gobierno mantener con ellos. ${ }^{26}$

Se trataba, entonces, de impedir que los mismos Wayuu tomaran las leyes en sus manos y aplicar las propias para satisfacer el agravio inferido por Rivera. En tal sentido, correspondía las autoridades de Sinamaica conciliar y tomar las medidas de seguridad necesarias para "prevenir los acontecimientos" que se esperaban por el disgusto de la parcialidad de Jusayu ${ }^{27}$. Vale decir que el indígena se presentó en la Comandancia "quejándose contra Manuel Rivera por haberle seducido a la mujer". También por negarse Rivera "a pagarle e esta" lo que le había prometido. Por lo que Jusayu "amenazando con que sino le satisface por Rivera el agravio que se le ha irrigado robará a su partida para la Guajira lo que le indemnice de lo que se prometió a la india." Ante lo cual Rivera se negó a contestar los cargos "alegando que tenía sus jueces naturales, con otras expresiones irrespetuosas”. En el oficio se instruía la

ni se les disguste, evitar los males que a esta población puede traer la enemistad de la tribu Jusayu por consecuencia de la injuria." Estas situaciones por ello no dejaron de presentarse. Comunicación del Juez de $1^{\circ}$ Instancia del Circuito Judicial del Este de la Provincia J. M. Valbuena al Gobernador de la Provincia en fecha 23 de noviembre de 1842 en la cual insertaba comunicación del Comandante de la Línea. A.H.Z. 1842, tomo 16, legajo 21, folio 231. El Decreto de 22 de Octubre de 1842 sobre los indios de la Guajira estipulaba en cuanto a las facultades de los funcionarios de Reducción en los negocios civiles y criminales de los indígenas. En: Armellada, 1977:121.

26. Expediente sobre caso de Rivera por Adulterio. Comunicación de fecha 23 de noviembre de 1842 en la cual insertaba comunicación del Comandante de la Línea. A.H.Z. 1842, tomo 16, legajo 21, folio 231. 
necesidad de llamar la atención "sobre el reclamo del pagamento que exige el indio" con la finalidad de evitar "la enemistad y prejuicios que la parcialidad de dicho indio pueda irrogar a este vecindario" ${ }^{28}$.

Sin embargo, en una comunicación de fecha 12 de diciembre de 1842 el Comandante de la línea Juan Macpherson el Gobernador de la Provincia le informaba que Manuel Rivera se presentó a la línea sin saber "de la manera en que ha sido puesto en libertad." Presumía, dicha autoridad, que era bajo fianza. La preocupación era reiterar "los temores que tengo fundadamente de que lo asesinen los indios si se presenta en las Guardias, con tanta más razón, cuanto que actualmente existen indios aquí de los agraviados que han (proyectado) matarlo" por la muerte de Jusayu ${ }^{29}$. El Gobernador Andrade opinaba diferente y pensaba que "estando Rivero en Sinamaica sea bien porque haya sido absuelto por el Tribunal competente, o bien por fianza que haya prestado", el Comandante debía tomar "las medidas de precaución que le dicte la prudencia evite a todo trance la desgracia" que dicha autoridad temía ${ }^{30}$. La parcialidad no se quedó tranquila y se presentaron en las Guardias de Afuera con el propósito de exigir compensación por la muerte del indio Manuel Carias o Jusayu, jefe de la parcialidad agraviada quienes "viniendo a llorar y sacar los huesos del difunto como es costumbre en ellos", resultaba que la misma "reclama el pago de su venida y aún de la muerte del mismo indio." Las razones estaban fundadas "en que el indio muerto por la detención que tuvo en el acontecimiento de Manuel Rivera con la india". Por ello, aún reclamaban por Rivera para que le diera compensación por la muerte del indígena ${ }^{31}$. Efectivamente, la parcialidad invadió el punto para

28. Comunicación del Juez Parroquial en Ejercicio Fermín Carvajal al Gobernador en fecha 10 de noviembre de 1842. Idem.

29. Comunicación de 12 de diciembre de 1842. Idem.

30. Comunicación del Gobernador Andrade al Comandante de la Línea 16 de diciembre de 1842. Idem.

31. Comunicación del Juez Parroquial en Ejercicio Fermín Carvajal al Juez de Primera Instancia del Circuito del Este en fecha 19 de noviembre de 1842. Idem. 


\section{EL TALLER DE LA HISTORIA 2}

vengar la muerte de su familiar; aunado a esto, Rivera se presentó en las Guardias a complicar más el asunto, desacatando lo que la autoridad civil le había prevenido de no presentarse en las guardias y obedecer al Comandante ${ }^{32}$.

La profusión de casos de justicia tuvo que resolverlos la autoridad de forma particular y otorgar la correspondiente indemnización, acudir a las leyes que muchas veces no respondían a las cordialidades entre las partes; y así mismo, obligaba a la parcialidad responder por los daños de un miembro ${ }^{33}$. En las Guardias, los casos más frecuentes eran los robos de ganado; estos no sólo eran de los indígenas a los vecinos de Sinamaica, sino que estos últimos muchas veces inducían a otros indígenas a robar a otras parcialidades para después comprar el robo ${ }^{34}$. Estas situaciones logran ex-

32. Informe del Primera Instancia del Circuito del Este al Gobernador de la Provincia en fecha 27 de diciembre de 1842. Idem.

33. Citaremos el caso del indígena Guarepe, que inutilizó una burra del señor Silva, y este solicitó el pago por parte del primero, este se internó en la Guajira temiendo que el dueño se la hiciese pagar. A su vez cuando se presentó Juan José un familiar y fue detenido para que pagara la indemnización y fue arrestado hasta que Guarepe viniese a responder por el animal que inutilizó. Sin embargo, las leyes no contemplaban lo que se debía hacer en estos casos porque "la muía fue inutilizada en un servicio prevenido por el mismo Silva", quien le ofreció a Henrique Weir la muía y el referido indígena como "baquiano" para trasladarse de las Guardias al Limón. Además no se aplicaban igualmente los artículos de la ley de 1842 a los indígenas que no se habían "reducido", por lo que se eximió a Juan José de pagar la indemnización. A.H.Z. 1843. Tomo 4, legajo 16.

34. En este caso podemos referir el siguiente expediente: el indígena Sermache de la parcialidad de los Urianas reclamó se le devolviese una burra que le robaron y “encontró en propiedad de José Manuel Delgado". La investigación sumaria hizo declarar al indígena Aniceto quien afirmó que "José Manuel Delgado le propuso que se robara uno para que se lo vendiese; que el indio entonces le ofreció que aquella noche le robaría un burro a un indio con quien estaba enojado, y seguramente la burra que Jurepeche mandó, fue la que había ofrecido robar". Así mismo se hizo comparecer a dos vecinos más, Pedro Lalinde y Narciso Flores quienes confirmaron el testimonio. El último afirmó además que "le oyó decir al indio Jurepeche, que Delgado le había ofrecido dos damezanas por la burra”. Jurepeche confirmó el testimonio atribuyéndole la culpabilidad al vecino, porque según él, Delgado antes de hacerle la proposición "le había dado aguardiente, ofreciéndole más cuando le enviara el burro, además de "una mochila de maíz y diez varas de cotón”. El responsable por supuesto negó que había 
plicarse porque los vecinos y algunos indígenas "integrados" al régimen civil de Sinamaica, fortalecieron ciertas prácticas perniciosas como la compra de efectos robados.

Otras situaciones eran las referidas a los homicidios que fueron los que más se contemplaron por los cobros o venganzas que hacían los Wayuu por los atropellos sufridos ${ }^{35}$. Otras causas fueron sobreseídas por falta de pruebas y para no dañar la reputación de las vecinas de Sinamaica, tal es el caso de María Altagracia Romero, a quien se sobreseyó para no "perjudicar la buena reputación y fama" de ésta, quien dio muerte a la indígena llamada Negrita, quien "era concubina de Pedro Paz", esposo de la primera, quien fue sorprendido por "su legítima mujer" en "mala disposición con la india, tanto que esta huyó desnuda y siguió corriendo hasta que dispararon los centinelas y cayó muerta". En este sentido, intervinieron en la muerte de Negrita la herida mortal proferida por la esposa de Pedro Paz con la daga, y el tiro de los centinelas porque no respondió al llamado de "quien vive: repetido tres veces" ${ }^{\prime 36}$.

Otras respondieron a causas contra los militares por atropellos contra indígenas; podemos mencionar sólo algunos casos que se lograron localizar, como el de Nonato Galué que dio muerte al

mandado a robar la burra. La autoridad resolvió la situación devolviendo la burra a su dueño y se emitió el expediente al juez Parroquial quien lo encontró culpable por lo que tuvo que pagar una multa por 25 pesos. A.H.Z. 1843, tomo 24, legajo 11 .

35. Estos expedientes son ricos, amplios y diversos y a modo de ejemplo la causa contra el indígena Martín Pacheco por cometer homicidio contra un indígena llamado Teniente y la causa que motivó la agresión contra Pacheco por parte de Teniente, fue según el autor del crimen por "la muerte dada por unos parientes suyos en años pasados a una mujer y a un niño de la parcialidad del Teniente, y cuya muerte quiso vengar él”. Este fue absuelto por defensa personal, a pesar de que el único testigo era un niño de 11 años, hijo de Teniente llamado Guanariguan quien atestiguó en su contra. Se tomo en consideración "una exuberante prueba de ser hombre de pacífico carácter, y por el contrario el indígena Teniente, díscolo y pendenciero, así como la enemistad capital que le profesaba el difunto. A.H.Z. 1844, tomo 6, legajo 67.

36. Sentencia dictada por Manuel María Martín Juez de Primera Instancia del Este en 24 de octubre de 1846. A.H.Z. 1846, tomo 3, legajo 26. 
76 EL TALLER DE LA HISTORIA 2

indio Causinapa, quien intentó huir del presidio en las Guardias de Afuera $^{37}$. Igualmente, Juan Macpherson no escapó de esta situación ya que fue denunciado por algunos hechos "entre los indígenas de la Guajira ${ }^{44}$ y el Comandante ${ }^{38}$. José Ángel Rodríguez también fue denunciado por algunos hechos como asesinato a un indígena, comerciar con los Wayuu lo cual le estaba prohibido ${ }^{39}$. Al parecer no se comprobó nada.

No hay que dejar de lado los frecuentes atropellos y muertes que sufrían algunos indígenas a causa del servicio personal ${ }^{40}$. Es-

37. Expediente en el cual se absuelve a Galué porque "obró según el principio de reconocimiento de una justa defensa contra una injusta agresión", Justificaba que Galué "se vio forzado al hecho" y se le liberó de cargo. 12 de febrero de 1845. A.H.Z. 1845 , tomo 11, legajo 10, folio 29.

38. Expediente de la causa contra Macpherson promovida por varios vecinos de Sinamaica en el cual rindieron declaración más de once testigos entre vecinos, militares e indígenas en 1844 y acusaron al Comandante de entregar dos indígenas jarariyues al indígena Guapo y este dio a Macpherson la indemnización para que se los diese con el fin de asesinarlos porque eran sus enemigos, lo que efectivamente hizo. Esta situación evidencia la alianza con la parcialidad del Guapo que propició esa irregularidad. Otro expediente en el año 1846 denunciaba el desacato de autoridad de Macpherson de entregar dos militares que había cometido atropellos contra indígenas. Estos factores incidieron para que en 02 de mayo de 1846 se solicitó la remoción del Comandante del la Línea porque las prácticas abusivas que estaba cometiendo produjo reclamaciones por parte de las parcialidades agraviadas de atacar si no se les indemnizaba por la muerte de los jarariyues, y por la decadencia del comercio guajiro. El Gobierno manifestaba que el Comandante Macpherson "no es de manera laguna a propósito para desempeñar las importantes funciones relativas a la reducción de los indígenas de Maracaibo., que sus actos violentos e inconsecuente proceder alejaban cada día más a las tribus guajiras del tráfico de Sinamaica y que su permanencia en aquel puesto compromete altamente la seguridad de Sinamaica, y aún la moralidad del gobierno de Venezuela." Se recomendó para sustituirlo a Narciso Gonell. A.H.Z. 1844, tomo 15, legajo 37, 1846, tomo 8, legajo 6, expediente de la causa contra Macpherson. Ministerio de Relaciones Exteriores, en adelante M.R.E. 1840-1870, tomo 249.

39. Expediente contra José Angel Rodríguez, Comandante de las Guardias de Afuera. A.H.Z. 1857, tomo 9, legajo 24. Continúa el expediente en A.H.Z. 1858, tomo 1, leg. 21.

40. Se denunció que los Montieles habían matado a un indígena sirviente llamado Jairao “que era peón del Señor Tomás Montiel y Pacho Montiel estos junto con otro familiar "lo amarraron y golpearon cruelmente, después de lo cual y cuando ya estaba próximo a morir lo echaron de la casa para que fuera a expirara a otro lugar". Hecho denunciado 
tas causas, de una u otra manera, revelan aspectos de la sociedad en estudio en cuanto a su organización jurídica. En ella regulan un conjunto de normas sociales que eran válidas a todos los Wayuu. Si se violaba el clan o parcialidad debía responder por los daños. Faltarían estudios específicos de este aspecto para profundizar en d impacto de esta normativa en la sociedad maracaibera. Las autoridades consideraban que:

...el guajiro es tan capaz de amistad como de odio y se conocerá desde luego que él posee un carácter que promete mucho para la reducción a la civilización, a que está llamado por el contacto y comunicación en que está con una nación que ni le insulta ni le oprime" 41 .

Siguiendo con las situaciones, otro caso fue del indígena José de la Rosa (posiblemente cocina) quien conmocionó a la población de Sinamaica y las autoridades venezolanas por la muerte que causó a José Agustín, joven de 15 años, a una indígena en el Limón y a su propia esposa. El Gobernador José A. Serrano refería sobre el caso:

Estos hechos califican al indio José de la Rosa de un insigne criminal de la República no deben permitir exista dentro de su territorio sin castigo, aparte de que la impunidad le alentará para nuevos delitos, obligando a los parientes de sus víctimas a tomar por si mismas las horribles venganzas que acostumbran los indígenas en desagravio; y de aquí la guerra intestina entre ellos y la extinción de algunas familias ${ }^{42}$.

Estas situaciones se hacían insostenibles para las autoridades. Por ello, se impidió la venta de fusiles y otras armas a los Wayuu y a los cocinas. En los casos citados, se puede observar que las leyes no dieron respuesta a todos los problemas de justicia que se presentaron lo que evidencia la complejidad de situaciones que se

por la indígena Isabel Machado y no aparece la sentencia, ni la averiguación de la misma. A.H.Z. tomo 8, legajo 6.

41. A.G.N. 1851, Interior y Justicia t. CDLII, folio 167.

42. Comunicación dirigida al Alcalde Parroquial en Ejercicio de Sinamaica en fecha 25 de febrero de 1847. A.H.Z. 1847, Caja 2, Carpeta $\mathrm{N}^{\mathrm{O}} 43$. 
presentaron; en algunos casos se debió conceder sobreseimiento y en otros impunidad. A pesar de los esfuerzos de los jueces por administrar justicia, en ocasiones fueron infructuosos por la limitación del desconocimiento del idioma de los encausados y el tener que acudir al intérprete para mediar el aspecto lingüístico ${ }^{43}$. En otros se consideraba la "insustancialidad" de los testimonios como insuficientes "para servir de fundamento a un juicio acertado". Esta situación hacía que en muchos casos se absolvieran ${ }^{44}$.

A esta situación contribuyó que los Wayuu acusados de un crimen "no llega a probárseles en juicio lo que requirió aprobar en 1855 la "Resolución Ejecutiva sobre lo que debe observarse con aquellos indígenas a quienes, acusados de un crimen no se les haya probado"45. El Gobernador de Maracaibo, como Director general de indígenas, consultó al Poder Ejecutivo la medida "contra aquellos indios goajiros ya reducidos que viven en parcialidades en la Villa de Sinamaica, cuando acusados por delitos graves y sometidos a un juicio formal, resultaban absueltos en definitiva por falta de pruebas legales, y regresaban a dicha Villa para ser una constante amenaza a la vida e intereses de sus habitantes". Por este motivo, se "propuso como un partido adoptable el destinarlos al servicio de hacendados de otras provincias y ración y sin sueldo" ${ }^{\text {"46. }}$

43. Sobreseimiento sobre el robo de una cabra por falta de intérpretes en el Tribunal en fecha 14 de diciembre de 1850. A.H.Z. 1850, tomo 12, legajo 22.

44. Los actos realizados por los Wayuu se explican según las autoridades "por su estado y costumbres salvajes, no infringen en la mente de aquellos sus ejecutores ningún derecho, porque ninguno conocen y no puede acarrearlo la pena que impone la ley a quien no se les ha sometido: que su idioma como exclusivo de ellos no es profesado en perfección por los que se dicen interpretes y esto impondría a incertidumbre la justicia que se administre fundada en la exactitud de las versiones que se hiciesen de sus testimonio o descargos". Por estas situaciones se sobreseyeron muchos casos, específicamente el abigeato cometido por los indígenas Cacio, Juan José y otros A.H.Z. 1852, tomo 25, legajo 66, tomo 17 , legajo 92.

45. Esta ley estipulaba que "vigilar la conducta del absuelto" para que no se repitieran las situaciones descritas. En: Fray Cesáreo de Armellada. Fuero Indígena Venezolano. (1977: 139-141).

46. Memoria de los Ministerios de Venezuela. 1855: 65-66. 
El Poder Ejecutivo opinaba que "la medida indicada por el señor Director rayaba en lo arbitrario", contraria a la "prudencia y tino con que debe procederse para alcanzar el alto fin de la educación civil y religiosa de aquellas tribus salvajes". El Consejo de Gobierno "resolvió negativamente dicha pretensión según pues en el Decreto Orgánico de aquellas Misiones se hallaban establecidas "las reglas relativas al procedimiento criminal contra los goajiros ya reducidos" e incorporados a las poblaciones del Estado. Igualmente era el Poder Judicial "el llamado a imponer penas y designar los lugares en que deben sufrirlas" 47 .

Se puede afirmar que la constante relación con los vecinos de Riohacha y Sinamaica propició cambios en la hospitalidad. (Cfr. Goiticoa, 1878: 6-7). La aplicación de los principios consuetudinarios adquirió matices diferentes, para el caso colombiano:

Si es cierto que ocurren algunas desavenencias entre civilizados y los indios que terminan a veces con robos, heridas y muertes, puede asegurarse que no son los indios los que toman la iniciativa en semejantes sucesos, a menos que se les ofenda en su dignidad personal, según sus leyes y costumbres, o en el pudor de sus mujeres de que son muy celosos, o que se embriaguen después de haber sido escamoteados en sus intereses, lo que es muy frecuente cuando las transacciones se verifican sin la vigilancia de las autoridades establecidas al efecto por el gobierno de Colombia. Para vengar a los indios muertos en las contiendas que se originan en esas desavenencias, o la sangre en ellas derramadas, ya no roban o matan como antes a todos los civilizados que encontraban, sin distinción de sexos, sino que persiguen sólo al agresor con tenaz actividad para matarlo, sino quisiere pagar la vida del muerto o la sangre vertida, por el valor que se deriva de las riquezas y las demás circunstancias de la víctima. (Idem.7-8)

Con respecto a estos cambios en la relación entre colombianos y Wayuu, los permanentes contactos con los mismos propiciaron un mestizaje intenso, se establecieron alianzas mediante el comercio:

47. Idem. 


\section{EL TALLER DE LA HISTORIA 2}

A partir de la segunda mitad del siglo XIX algunos colonos de Ríohacha se establecieron en el territorio guajiro, dedicados tanto al comercio de dividivi, aguardiente, y ganado como a la explotación de sal y perlas. El dividivi, un producto natural recolectado por los nativos, se utilizó en las labores de curtiembre de cueros, cuya demanda había sido iniciada por una casa comercial de Curaçao en 1850. la comercialización clandestina por parte de los Riohacheros se efectuaba en los puertos del norte bajo el necesario amparo de los guajiros. Por otra parte las frecuentes contiendas civiles colombianas llevaron a muchos comerciantes a establecer sus almacenes en tierra de los indígenas, para preservarlos de la confiscación y otros peligros de las guerras. Como consecuencia de ello, se realizaron diversas alianzas matrimoniales entre criollos e indígenas, de lo que surgieron algunos de los grandes troncos familiares mestizos del norte de la península. Lo anterior implico que en algunas zonas se diese una transitoria revitalización de la economía de los guajiros, así como la introducción de variaciones locales en su modelo de organización social, pero a la postre todo ello resulto en una mas profunda inserción de los nativos en el sistema económico y social de la República. (Guerra Cúrvelo, 1992:70).

A partir de 1850 se expandió Colombia en su área de influencia y es así como funda poblados como El Paso, El Soldado. Vene-

zuela, por el contrario, estableció una línea de control militar y comercial, espacio que impidió un sincretismo social mayor.

Como se ha dicho, los Wayuu poseían sus propios cánones y escala de valores en derecho, moral, religión y economía. Sus decisiones exhiben un fondo de justicia universal. (Reimán, 1975:65). Las diferencias socioculturales de los Wayuu y actuación de algunas autoridades permiten explicar la dinámica de esa región orientada por la actividad comercial. Las dificultades se presentaron o aumentaron a medida que las autoridades de la Provincia de Maracaibo debía hacer cumplir las medidas del Estado que no consideraba la realidad presente en tomo a Sinamaica y las Guardias de Afuera.

Era evidente la necesidad de la República de Venezuela de controlar un espacio tan importante desde el punto de vista 
geopolítico y económico. Pero la mayoría de la legislación no dio los resultados esperados por no considerar la relación social existente como se ha explicado. Sin embargo, en tomo a estas disposiciones, actuaciones de autoridades blancas y resistencia Wayuu, se desarrollaron los vínculos, acuerdos y tensiones en las primeras décadas del siglo XIX. Para ilustrarlo, es necesario analizar las disposiciones venezolanas para el control de esta comunidad, proceso que sería simultáneo a los esfuerzos por incentivar el importante comercio que se realizaba con los Wayuu e intentos por ejecutar acciones conciliatorias para propiciar alianzas con algunas parcialidades.

\section{CONCLUSIONES}

El comportamiento y resistencia de los Wayuu ante las medidas impuestas por el Estado venezolano se explica por la capacidad de la sociedad de adaptarse a la realidad cambiante. En este sentido, generó normas de conducta específicas de acuerdo a las leyes y costumbres ancestrales que permitieron la defensa de su soberanía e integridad. Aprovecharon, para mantener la resistencia durante estos años de la república, distintos recursos como la preservación y conocimiento del territorio, la diversificación de actividades económicas para su subsistencia, el patrón de asentamiento distribuido según los recursos y cosmogonía, la ley consuetudinaria que obligaba a indemnizar los agravios cometidos $y$, por último, la organización política descentralizada.

La inexistencia de una autoridad general para todos los Wayuu y la especificidad cultural de la sociedad, fueron elementos que, por una parte, impidieron concretar efectivamente las medidas de control político administrativo y militar del gobierno venezolano $y$, por otra, imposibilitaron una definitiva alianza entre las parcialidades para constituir un único frente de resistencia realidad aprovechada por el gobierno marabino. La conciliación entre las leyes venezolanas y la "Ley Guajira" fue quizás uno de los recursos más valiosos para lograr una relativa paz entre los sectores involucrados. 


\section{EL TALLER DE LA HISTORIA 2}

\section{BIBLIOGRAFIA}

Amodio, Enmanuele. 1993. Formas de la Alteridad. Construcción y Difusión de la imagen del indio americano en Europa durante el primer siglo de la conquista de América. Ediciones Abya-yala. Quito.

Amodio, Enmanuele. 1988. Cultura, Oficina Regional de Educación para la América Latina y el Caribe (OREALC), Santiago de Chile.

Armellada, Cesáreo Fray. 1977. Fuero Indígena Venezolano 1811-1977, Caracas: Universidad Católica Andrés Bello.

Benites, Rafael. 1975. "Recuerdos de mis Viajes a la Guajira y noticias recogidas de paso". En: Vila, Marco Aurelio. La Guajira en 1874. Publicaciones de la Universidad del Zulia. Maracaibo.

Bonilla, Heraclio. Armando Guerrero (editores), Antonio Escobar Ohmstede, Guido Barona Becerra y otros. 1996. Los pueblos campesinos de las Américas, etnicidad, cultura e historia en el siglo XIX. Universidad Industrial de Santander.

Cardozo Galúe, Germán. 1990. Maracaibo y su Región Histórica. El Circuito Agroexportador. 1830-1860, Maracaibo. Ediluz.

Codazzi, Agustín. 1951. Resumen de la Geografía de Venezuela. Obras Completas. 3 tomos. Ediciones del Ministerio de Educación. Caracas.

Cunill, Grau. 1987. Geografía del poblamiento venezolano en el siglo XIX. Tres tomos, Caracas: Ediciones de la Presidencia de la República.

Diario de Avisos y Semanario de las Provincias, "Comunicados. Guajira". Caracas, 27 de febrero de $1858, \mathrm{~N}^{\mathrm{O}} 35$.

El Zulia Ilustrado. "Reseña de los usos y costumbres de los indígenas guajiros e indicaciones para su reducción y civilización". Emitida por el Ministerio de Fomento del Estado Zulia, con fecha 25 de enero de 1874 a la Dirección General de Estadística de la República (versión corregida, ampliada y aumentada). Director E. López Rivas. $\mathrm{N}^{\circ}$ 24. Maracaibo, 30 de noviembre de 1890. pp. 192-194; $\mathrm{N}^{\mathrm{O}} 25$. Maracaibo, 31 de diciembre de 1890, pp. 205-206.

Goiticoa Alejandro. 1878. La guajira y los puertos de Occidente. El Territorio Federal de la Guajira. Apertura de los puertos de la Vela y Maracaibo. La Bahía de Cojoro como punto de escala. Ventajas para la República del establecimiento de la aduana en Cojoro. Caracas, Imprenta de Espinal e hijos.

Guerra Cúrvelo, Weilder. 1993. "El poblamiento del Territorio". En: Vivienda Guajira, Ediciones Carbocol, Colombia.

Jahn, Alfredo. 1973. Los aborígenes del Occidente de Venezuela, Su Historia, Etnografía y afinidades lingüísticas. Caracas: Monte Ávila Editores.

Las Estadísticas de las Provincias en la época de Páez. 1973. Biblioteca de la Academia Nacional de la Historia. Fuentes para la Historia Republicana de Venezuela, Caracas. 


\section{CARMEN LAURA PAZ REVEROL 83}

La Mariposa, "Artículos remitidos: Guajira. Contrabando". Maracaibo, 25 de junio de 1842. Imprenta de Miguel A. Baralt. $\mathrm{N}^{\circ} 45$.

La Opinión Nacional, “Apuntes Guajiros” por Juan Macpherson. Caracas, 7 de Agosto de 1877. $\mathrm{N}^{\mathrm{O}} 2.473$.

Matos Romero, Manuel. 1975. Wñiasus Woúmain ("La sedienta guajira”). Universidad del Zulia, Maracaibo, Venezuela.

Matos Romero, Manuel. 1975. Derecho Civil y Penal Guajiro El "Putchipu” o Abogado Guajiro. (Estudio sobre el derecho oral o tradicional guajiro y la función que desempeña el "putchipu" o abogado dentro de la comunidad indígena). Maracaibo, Venezuela.

Memorias de los Ministerios de Venezuela. Ministerio del Interior y Justicia. 1855. Imprenta Carreño Hermano, Calle del Comercio, $\mathrm{N}^{\mathrm{O}}$ 149. Caracas, pp. 65-66.

Paz Ipuana, Ramón. Mitos, Cuentos y Leyendas Guajiros. Instituto Agrario Nacional, Caracas, Venezuela.

Perrin, Michel. 1989. "Creaciones míticas y representaciones del mundo: el hombre blanco en la simbología guajiro". En: Revista Antropológica. $\mathrm{N}^{\mathrm{O}} 72$, pp. 41-60. Caracas.

Plumacher, Eugene H. 1877-1890. Memoir. Tennessee State Library and Archives. Nashville. Manuscript. Microfilm.

Purdi, Janet R. 1987. "Relaciones entre los guajiros y el hombre blanco". Universidad Católica Andrés Bello, Facultad de Humanidades y Educación. Institutos humanísticos de investigación. En: Montalban $\mathrm{N}^{\mathrm{O}} 19$, pp. 133-160.

Reclus., E. 1936. Voyage a la Sierra Nevada de Sainte-Marthe; paysages de la nature tropicale. Traducción castellana por Gregorio Obregón, Bogotá.

Reimán, Antonio Antileo. 1975. "Rol de las Leyes en la población indígena de América". En: América Indígena. Vol. XXXV, $\mathrm{N}^{2} 1$, enero-marzo.

Sahler, Benson, 1988. Los Wayuu (goajiro) En: Los Aborígenes de Venezuela, Fundación La Salle, Monte Avila Editores, Caracas.

Valenzuela Arce, José Manuel. 1996. "Etnia y Nación en la frontera de México-Estados Unidos”. Culturas en Globalización. América Latina-Europa-Estados Unidos. Libre comercio e integración, Caracas, Editorial Nueva Sociedad, García Canclini, Néstor (Coord.)

Vila, Marco Aurelio. 1957. La Guajira en 1874. Publicaciones de la Universidad del Zulia. Maracaibo. 